\title{
Effect of Synthesis Method and Melamine Content of Melamine-Urea-Formaldehyde Resins on Bond-Line Features in Plywood ${ }^{1}$
}

\author{
Muhammad Adly Rahandi $\mathrm{LUBIS}^{2} \cdot$ Bora $\mathrm{JEONG}^{2} \cdot$ Byung-Dae PARK(D ${ }^{2, \dagger}$ • \\ Sang-Min $\mathrm{LEE}^{3} \cdot$ Eun-Chang $\mathrm{KANG}^{3}$
}

\begin{abstract}
This work examined effects of the synthesis method and melamine content of melamine-urea-formaldehyde (MUF) resins on the bond-line features (i.e. resin penetration and bond-line thickness) in plywood. Two synthesis methods (MUF-A and MUF-B) and three melamine contents (5, 10, and 20\%) were employed to prepare MUF resins. The MUF-A resins at three melamine contents were prepared by a simultaneous reaction of melamine, urea, and formaldehyde, while the MFU-B resins were prepared by reacting melamine at the same levels with formaldehyde followed by urea. The results showed that higher melamine content increased the viscosity of MUF-A and MUF-B resins. The resin penetration of MUF-A resins decreased by $48 \%$ while those of MUF-B resins increased by $16 \%$ at $20 \%$ melamine content. As a result, the MUF-A resins had greater bond-line thickness than those of MUF-B resins as the melamine content increased. The MUF-B resins resulted in thinner bond-line and greater resin penetration compared to those of MUF-A resins. The results suggested that MUF-B resins prepared with $20 \%$ melamine content had a proper combination of resin penetration and bond-line thickness that could produce plywood panel with a better adhesion performance.
\end{abstract}

Keywords: MUF resins, bond-line thickness, resin penetration, light microscopy, plywood

\section{INTRODUCTION}

Bonding of wood is a complex process that involves adhesion between wood and adhesive, and cohesion of the adhesive itself (Hunt et al., 2019). To obtain a good bonding, an adhesive should have a sufficient penetration into wood tissues, such as tracheids and infiltration cell walls (Kamke and Lee, 2007). Many factors are affecting the penetration of adhesives into wood, such as molecular weight (MW), chemical structure, viscosity, solids content, reactivity, $\mathrm{pH}$, solubility, and surface tension of adhesives (Hunt et al., 2019). A good insight on these factors and its relation with adhesive penetration would provide better understanding of wood bonding. Therefore, an efficient utilization of wood resources and the improvement on durability of wood-based panel products could be achieved by understanding the interaction between

\footnotetext{
${ }^{1}$ Date Received May 7, 2019, Date Accepted August 10, 2019

2 Department of Wood and Paper Sciences, Kyungpook National University, Daegu, Republic of Korea

${ }^{3}$ Wood Utilization Division, National Institute of Forest Science, Seoul, Republic of Korea

† Corresponding author: Byung-Dae PARK (e-mail: byungdae@knu.ac.kr, ORCID: 0000-0002-9802-7855)
} 
wood and wood adhesives, particularly at the bond-line (Marra, 1992; Frihart, 2009, 2015). Wood-based panel industry have utilized urea-formaldehyde (UF), phenolformaldehyde (PF), and melamine-formaldehyde (MF) resins as the main adhesive particularly to produce plywood, particleboard, oriented strand board, and medium density fiberboard (Hartono et al., 2016; Hong et al., 2017; Hong and Park, 2017; Maulana et al., 2017).

Among formaldehyde-based adhesives, melamineurea-formaldehyde (MUF) resins are designed to substitute the high cost MF and PF resins (Hartono et al., 2016; Pizzi and Mittal, 2003), and to improve low water resistance and to reduce the formaldehyde emission of UF resins (Jeong and Park, 2019; Lubis et al., 2019; Park et al., 2016; Pizzi and Mittal, 2003). With the consideration of lower cost and better performance of MUF resins than MF or PF resin adhesives, research have been focused on, their synthesis method (Hong et al., 2017; Mao et al., 2013), structure and properties (Jeong and Park, 2017, 2016; Liu et al., 2016), thermal behavior (Siimer et al., 2010), hydrolytic stability (Park et al., 2009), and their performance in plywood (Su et al., 1998; Hse and Higuchi, 2010).

As the resin penetration has an important role in the adhesion of plywood, a sufficient resin penetration could improve the adhesion strength of plywood, while an excessive penetration resulted in a poor adhesion strength (Hong and Park, 2017; Nuryawan et al., 2014). Therefore, the penetration of MUF resins is becoming a particular interest. For example, MUF resin distributions in medium density fiberboard panel have been examined using confocal laser scanning microscopy technique with an aid of adding $0.01 \%$ toluidine blue O to identify the resins (Cyr et al., 2006). But, there is a very limited report on the MUF resin penetration for plywood. Most of studies focused on the penetration of UF resins (Sernek et al., 1999; Nuryawan et al., 2014). Therefore, this work was done to evaluate the bond-line features of MUF resins in plywood as a function of the synthesis method and melamine content using light microscope technique. In addition, the relationship between bond-line features and properties of MUF resins was also investigated to have a better understanding.

\section{MATERIALS and METHODS}

\subsection{Materials}

The materials used for the synthesis of MUF resins were technical grade of melamine (99 wt\%), urea granules (99 wt\%), formalin (37 wt\%) aqueous formic acid solution (20 wt\%), and sodium hydroxide solution (20 wt\%). An aqueous ammonium chloride solution (20 wt\%) was used as hardener. These chemicals were purchased Duksan or Daejung Chemical, Korea. Radiata pine (Pinus Radiata D. Don) veneers (6.2\% of moisture content) were used to prepare three-ply plywood.

\subsection{Synthesis of MUF resins}

MUF-A resins at three melamine contents $(5,10$, and $20 \%$ ) were prepared by a simultaneous reaction of melamine, urea, and formaldehyde, while MUF-B resins were prepared by reacting melamine at the same level with formaldehyde followed by urea. Briefly, MUF-A resins were synthesized using an alkalineacid-alkaline three-step reaction. Around $580 \mathrm{~g}$ formalin was placed in a reactor, and the $\mathrm{pH}$ was adjusted to 8.2-8.5 using sodium hydroxide. A calculated amount of the first urea was added into the reactor under continuous stirring at $40^{\circ} \mathrm{C}$ to obtain $1.5 \mathrm{~F} /(\mathrm{U}+\mathrm{M})$ mole ratio. Different melamine contents (5, 10 and $20 \mathrm{wt} \%$ ) was added to the reactor. After maintaining the temperature at $90^{\circ} \mathrm{C}$ for $1 \mathrm{~h}$, the $\mathrm{pH}$ value was adjusted to 6.5 with formic acid for condensation reaction. The temperature was maintained at $90^{\circ} \mathrm{C}$ until reaching the water-tolerance value of $100-120 \%$, and the target vis- 
Effect of Synthesis Method and Melamine Content of Melamine-Urea-Formaldehyde Resins on Bond-Line Features in Plywood

cosity between the ' $\mathrm{B}$ ' and ' $\mathrm{C}$ ' as measured by a bubble viscometer (VG-9100, Gardner-Holdt Viscometer, FL, United States). Furthermore, the $\mathrm{pH}$ value was adjusted to 7.5 to 8.0 with sodium hydroxide, and a calculated amount of the second urea was added to prepare MUF-A resins with final $\mathrm{F} /(\mathrm{U}+\mathrm{M})$ mole ratio of 1.0. The temperature was set and maintained at $60^{\circ} \mathrm{C}$ for $20 \mathrm{~min}$, and $\mathrm{pH}$ value was adjusted to 9.0 to 9.2. MUF-A resins were cooled to ambient temperature prior to analysis.

MUF-B resins were prepared by adding formalin into the reactor, and the $\mathrm{pH}$ was adjusted to $8.2-8.5$ by adding sodium hydroxide. A calculated amount of melamine at three levels (5, 10 and $20 \mathrm{wt} \%)$ was added into the reactor at $40^{\circ} \mathrm{C}$ to produce MUF-B resins. Temperature was maintained at $90^{\circ} \mathrm{C}$ until reaching the same target viscosity as MUF-A resins. The first urea was added during the second stage to obtain $\mathrm{F} /(\mathrm{U}+\mathrm{M})$ ratio of 1.5 , and the $\mathrm{pH}$ value was adjusted to 6.5 with formic acid for condensation. MFU resins were prepared with the same water-tolerance value and target viscosity as the MUF resins. Furthermore, a calculated amount of the second urea was added to prepare MUF-B resins with final $\mathrm{F} /(\mathrm{U}+\mathrm{M})$ mole ratio of 1.0. The temperature was set and maintained at $60^{\circ} \mathrm{C}$ for $20 \mathrm{~min}$, and $\mathrm{pH}$ value was adjusted to 9.0 to 9.2. MUF-B resins were cooled to ambient temperature prior to analysis.

\subsection{Preparation of plywood}

Three-ply plywood panels were prepared using Radiata pine (Pinus radiata D. Don) veneer (300 mm $\times 300 \mathrm{~mm} \times 2 \mathrm{~mm}$ ) and two types of MUF resins, namely MUF-A and MUF-B. The glue mix was prepared by mixing the resins with $3 \% \mathrm{NH}_{4} \mathrm{Cl}$ (based on the non-volatile solids content of MUF-A and MUF-B resins) and $10 \%$ wheat flour (based on the total weight of resins with the resins). The glue mix was spread on the veneer at a glue spread of $170 \mathrm{~g} / \mathrm{m}^{2}$. Plywood were cold-pressed under a pressure of $8 \mathrm{kgf} / \mathrm{cm}^{2}$ for
$20 \mathrm{~min}$, and then hot-pressed at $120^{\circ} \mathrm{C}$ under the same pressure for $4 \mathrm{~min}$ and at $40 \mathrm{~s} / \mathrm{mm}$ of pressing factor.

\subsection{Properties of MUF resins}

The viscosity of MUF-A and MUF-B resins was measured using a cone-plate viscometer (DV-II+, Brookfield, MA, United States) with spindle No. 2 at $25^{\circ} \mathrm{C}$ under $60 \mathrm{rpm}$. The non-volatile solids content of both resins was obtained by drying $1 \mathrm{~g}$ of the sample in an oven at $105^{\circ} \mathrm{C}$ for $3 \mathrm{~h}$ and dividing the oven-dried weight with the initial weight. The gelation time of the resins was measured at $100^{\circ} \mathrm{C}$ by adding $3 \% \mathrm{NH}_{4} \mathrm{Cl}$ based on resins solids content using a gel time meter (DAVIS, Sunshine Instruments, United States). Water tolerance of MUF-A and MUF-Bresins after preparation was determined by adding certain amount of water into $1 \mathrm{~g}$ resins in the tube at $20^{\circ} \mathrm{C}$ until the resins appearance changing from transparent to cloudy.

\subsection{Measurements of bond-line features using light microscope}

The cross sections (thickness: $70 \mu \mathrm{m}$ ) of three-ply plywood were prepared to examine the bond-line features under a light microscope (LM) (Olympus Optical Co, Ltd., Tokyo, Japan) according to the published method (Singh et al., 2008; Nuryawan et al., 2014). The images were digitally captured at 20 different sections to obtain 20 image replications for each experimental unit. Furthermore, the bond-line thickness was defined by marking a clear boundary between the empty tracheids (without resins) and the edge of other veneer. The depth of resin penetration was determined by measuring the linear distance between the center of the bond-line and the resins that penetrated into the tracheids. Image-processing software (IMT solution ver.22.5, British Columbia, Canada) was used to obtain an average value and standard deviation for the resin penetration and bond-line thickness of MUF-A and MUF-B resins in plywood. 
Muhammad Adly Rahandi LUBIS · Bora JEONG • Byung-Dae PARK • Sang-Min LEE • Eun-Chang KANG

Table 1. Properties of MUF resins prepared with different synthesis methods and melamine contents

\begin{tabular}{|c|c|c|c|c|c|c|c|}
\hline Resin type & $\begin{array}{c}\text { Final } \\
\mathrm{F} /(\mathrm{U}+\mathrm{M}) \\
\text { mole ratio }\end{array}$ & $\begin{array}{c}\text { Melamine } \\
\text { content (\%) }\end{array}$ & $\begin{array}{l}\text { Non-volatile } \\
\text { solids content } \\
\text { (\%) }\end{array}$ & $\begin{array}{l}\text { Gelation time } \\
\text { (s) }\end{array}$ & $\begin{array}{l}\text { Viscosity } \\
(\mathrm{mPa} \cdot \mathrm{s})\end{array}$ & $\mathrm{pH}$ & $\begin{array}{c}\text { Water } \\
\text { tolerance (\%) }\end{array}$ \\
\hline \multirow{3}{*}{ MUF-A } & \multirow{3}{*}{1.0} & 5 & $61.6 \pm 0.1$ & $204 \pm 2$ & 58 & 9.3 & 100 \\
\hline & & 10 & $61.7 \pm 0.1$ & $174 \pm 3$ & 65 & 9.3 & 80 \\
\hline & & 20 & $61.9 \pm 0.2$ & $134 \pm 2$ & 84 & 9.3 & 30 \\
\hline \multirow{3}{*}{ MUF-B } & \multirow{3}{*}{1.0} & 5 & $59.7 \pm 0.1$ & $197 \pm 3$ & 57 & 8.9 & 160 \\
\hline & & 10 & $60.1 \pm 0.1$ & $168 \pm 3$ & 64 & 9.0 & 100 \\
\hline & & 20 & $61.0 \pm 0.1$ & $106 \pm 2$ & 84 & 9.3 & 30 \\
\hline
\end{tabular}

\section{RESULTS and DISCUSSION}

\subsection{Properties of MUF resins}

Properties of MUF-A and MUF-B resins at different melamine contents are presented in Table 1 . The non-volatile solids content, viscosity, and $\mathrm{pH}$ of MUF-A and MUF-B increased as the melamine content increased. As a result, the gelation time of both resins decreased with an increase in the content of melamine, indicating that higher melamine content increased the reactivity of resins (Tohmura et al., 2001). Further, an increase in the melamine content resulted in low water tolerance, indicating higher melamine had more branched structure and high reactivity (Properzi et al., 2001).

\subsection{Bond-line features of MUF resins}

Light micrographs shown in Fig. 1 clearly show the bond-line structure, including empty tracheids (arrow), filled tracheids (arrow head), bond-line (red line), and the edge of other veneer in plywood (star). The linear red lines in the bond-line enabled to measure both bond-line thickness and resin penetration of MUF resins in plywood. The measurement was done for plywood panels bonded with MUF-A and MUF-B resins prepared by different synthesis methods and melamine contents.

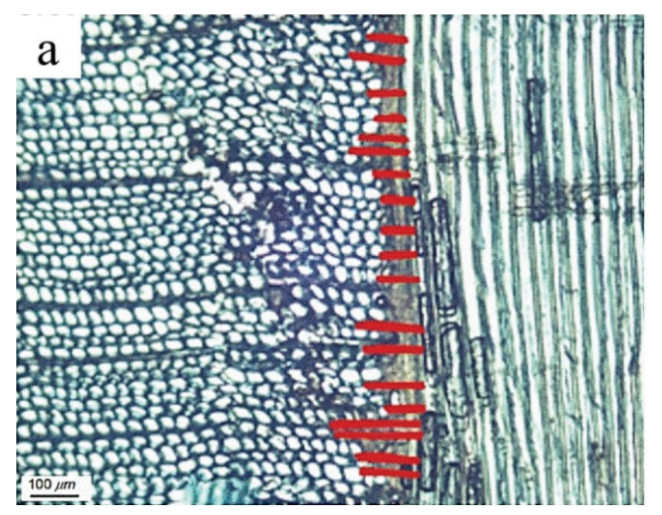

(a)

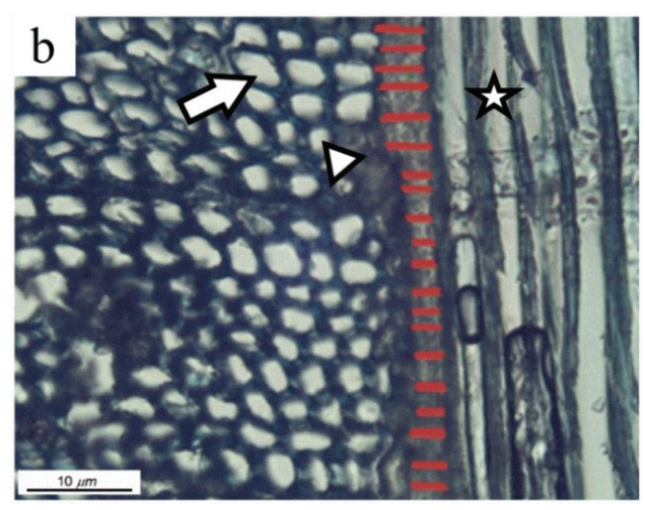

(b)

Fig. 1. Typical light micrographs of (a) resin penetration, and (b) bond-line thickness of MUF resins in plywood. 
Effect of Synthesis Method and Melamine Content of Melamine-Urea-Formaldehyde Resins on Bond-Line Features in Plywood

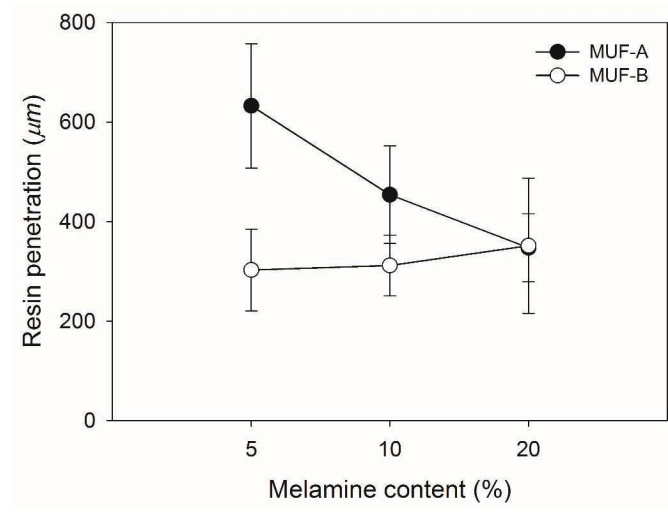

Fig. 2. Resin penetration of MUF resins in plywood prepared by different synthesis methods and melamine contents.

The resin penetration of MUF-A resins decreased as the melamine content increased, while an opposite trend was observed for MUF-B resins (Fig. 2). This might be due to that different synthesis methods resulted in different MWs, chemical species, and compositions of MUF-A and MUF-B resins (Properzi et al., 2001; Mao et al., 2013). The resin penetration of MUF-B resins increased by $15 \%$ only at $20 \%$ melamine content. This meant that the addition of urea after the reaction between melamine and formaldehyde resulted in greater fraction of low MW. Therefore, only low MW chemical species from MUF-B penetrated into the cell walls of tracheids, while the high MW chemical species stayed in the bond-line.

These results showed a decrease in bond-line thickness of MUF-B resins as the melamine content increased (Fig. 3). In addition, the bond-line thickness of MUF-A and MUF-B resins in plywood was ten times lower than the published results (Sernek et al., 1999; Nuryawan et al., 2014). It might be due to that the MUF-A and MUF-B resins had low viscosity at around $57 \sim 84$ mPas (Table 1). This studyshowed that reacting melamine together with urea and formaldehyde at the same stage (MUF-A) resulted in thicker bond-line and less resin penetration as a function of the melamine content, while

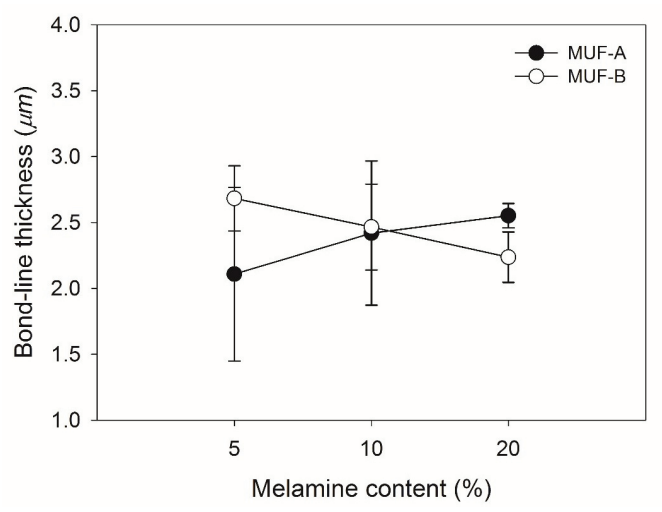

Fig. 3. Bond-line thickness of two types of MUF resins in plywood.

the opposite trend was true for MUF-B resins. The results of this study showed a similar trend with the bond-line features of MUF resins in parallel plywood (Jeong et al., 2019).

As shown in Fig. 4, the relationship between the resin penetration and viscosity of MUF-A and MUF-B resins was evaluated to understand the influence of bond-line features of these resins in plywood. The resin penetration of MUF-A resins decreased because higher melamine content increased the resin's viscosity. However, this is not the case for MUF-B resins. This could be due to the MUF-B resins has thinner bond-

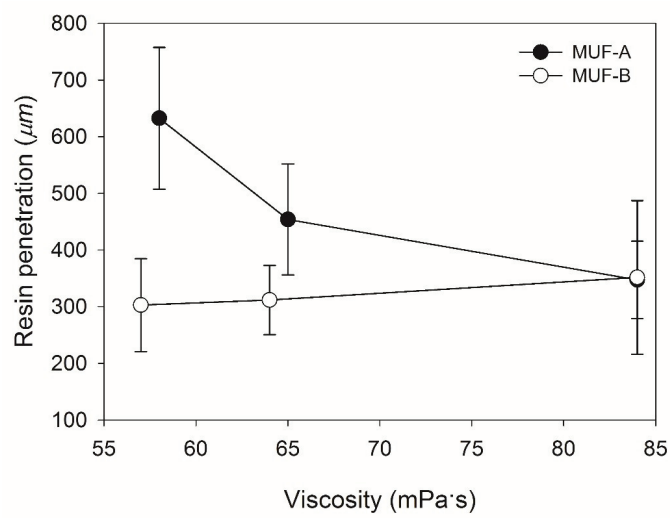

Fig. 4. Relationship between resin penetration and viscosity of MUF resins prepared with different synthesis methods and melamine contents. 


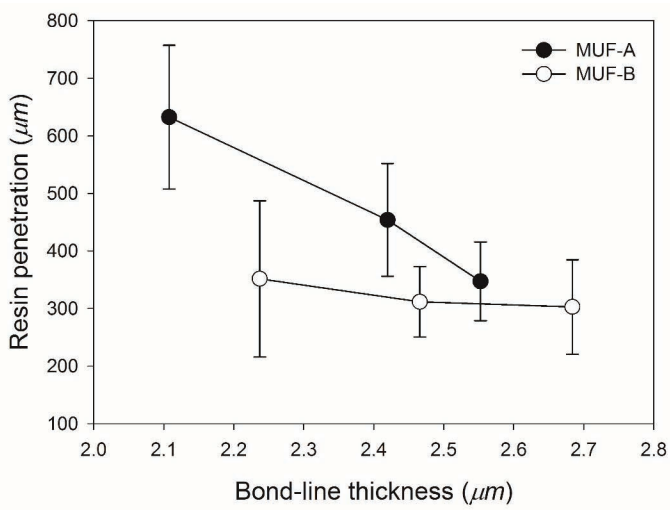

Fig. 5. Relationship between resin penetration and bond-line thickness of two types of MUF resins in plywood.

line than those of MUF-A resins at 20\% melamine content (Fig. 3), allowing more resins to penetrate into the cell walls of tracheids. Moreover, synthesis method also affects the development of MUF resins polymer. It was found that an initial reaction of melamine with formaldehyde, and then followed by urea (MUF-B) resulted in thinner bond-line and greater resin penetration compared to the resins prepared by reacting melamine, formaldehyde, and urea together at the same time (MUF-A).

As can be seen in Fig. 5, both MUF-A and MUF-B resins decreased in resin penetration as the bond-line thickness increased. This result was in accordance with the published report (Nuryawan et al., 2014; Jeong et al., 2019), and followed the general theory (Sernek et al., 1999; Hunt et al., 2019). Although both MUF-A and MUF-B resins had a quite similar solids content, $\mathrm{pH}$, and viscosity (Table 1), MUF-A and MUF-B resins could have different chemical structures and MWs due to the synthesis method (Mao et al., 2013). In addition, many other factors are affecting the penetration of adhesives into wood, such as the reactivity, solubility, and surface tension of adhesives (Hunt et al., 2019). Starved bond-line typically shows cohesive failure while thick bond-line is also weak and eventually waste the resins (Nuryawan et al., 2014). Therefore, determination of proper resin penetration and bond-line thickness could improve the efficient use of MUF resins in plywood manufacture.

\section{CONCLUSION}

Bond-line features of two types of MUF resins prepared with different synthesis methods and melamine contents have been investigated for plywood using light microscope. Although MUF-A and MUF-B resins had quite similar solids content, gelation time, $\mathrm{pH}$, and viscosity, both resins had different bond-line features at different melamine contents. Higher melamine content resulted in thinner bond-line and greater resin penetration for MUF-B resins, while the opposite trend was found for MUF-A resins. This study showed that an initial reaction of melamine with formaldehyde, and then followed by urea (MUF-B) resulted in thinner bond-line and greater resin penetration compared to the resins prepared by reacting melamine, formaldehyde, and urea together at the same time (MUF-A). The results suggested that MUF-B resins prepared with 20\% melamine content had a proper combination of resin penetration and bond-line thickness that could produce plywood panel with a better adhesion performance.

\section{REFERENCES}

Cyr, P.L., Riedl, B., Wang, X.M., Shaler, S. 2006. Urea-melamine-formaldehyde (UMF) resin penetration in medium-density fiberboard (MDF) wood fibers. Journal of Adhesion Science and Technology 20: 787-801.

Frihart, C.R. 2015. Introduction to Special Issue: Wood Adhesives: Past, Present, and Future. Forest Products Journal 65: 4-8.

Frihart, C.R. 2009. Adhesive groups and how they relate to the durability of bonded wood. Journal of 
Effect of Synthesis Method and Melamine Content of Melamine-Urea-Formaldehyde Resins on Bond-Line Features in Plywood

Adhesion Science and Technology 23: 601-617. Hartono, R., Hidayat, W., Wahyudi, I., Febrianto, F., Dwianto, W., Jang, J.H., Kim, N.H. 2016. Effect of phenol formaldehyde impregnation on the physical and mechanical properties of soft-inner part of oil palm trunk. Journal of the Korean Wood Science and Technology 44(6): 842-851.

Hong, M.K., Lubis, M.A.R., Park, B.D. 2017. Effect of panel density and resin content on properties of medium density fiberboard. Journal of the Korean Wood Science and Technology 45(4): 444-445.

Hong, M.K, Park, B.D. 2017. Effect of Urea-Formaldehyde Resin Adhesive Viscosity on Plywood Adhesion. Journal of the Korean Wood Science and Technology 45(2): 223-231.

Hong, M.K., Park, B.D., Kim, K.H., Shim, K. 2017. Performance of melamine-urea-formaldehyde resin adhesives at various melamine contents for bonding glued laminated timber under high frequency heating. Journal of the Korean Wood Science and Technology 45(4): 409-418.

Hse, C.-Y., Higuchi, M. 2010. Melamine-Bridged Alkyl Resorcinol Modified Urea-Formaldehyde Resin for Bonding Hardwood Plywood. Journal of Applied Polymer Science 16: 2840-2845.

Hunt, C.G., Frihart, C.R., Dunky, M., Rohumaa, A. 2019. Understanding Wood Bonds-Going Beyond What Meets the Eye: A Critical Review. Reviews of Adhesion and Adhesives 6: 369-440.

Jeong, B., Park, B.D., Causin, V. 2019. Influence of Synthesis Method and Melamine Content of UreaMelamine-Formaldehyde Resins to Their Features in Cohesion, Interphase, and Adhesion Performance. Journal of Industrial and Engineering Chemistry. https://doi.org/10.1016/j.jiec.2019.05.017. Jeong, B., Park, B.D. 2019. Performance of Urea-Formaldehyde Resins Synthesized at Two Different Low Molar Ratios with Different Numbers of Urea
Addition. Journal of the Korean Wood Science and Technology 47(2): 221-228.

Jeong, B.D, Park, B.D. 2017. Effect of analytical parameters of gel permeation chromatography on molecular weight measurements of urea-formaldehyde resins. Journal of the Korean Wood Science and Technology 45: 471-481.

Jeong, B., Park, B.D. 2016. Measurement of molecular weights of melamine-urea-formaldehyde resins and their influences to properties of medium density fiberboards. Journal of the Korean Wood Science and Technology 44(6): 913-922.

Kamke, F. a., Lee, J.N. 2007. Adhesive penetration in wood: a review. Wood and Fiber Science 39: 205-220.

Liu, Y., Zhao, X., Ye, L. 2016. A Novel Elastic UreaMelamine-Formaldehyde Foam: Structure and Properties. Industrial \& Engineering Chemistry Research 55: 8743-8750.

Lubis, M.A.R., Park, B.D., Lee, S.M. 2019. Performance of Hybrid Adhesives of Blocked-pMDI/MelamineUrea-Formaldehyde Resins for the Surface Lamination on Plywood. Journal of the Korean Wood Science and Technology 47(2): 200-209.

Mao, A., Hassan, E.B., Kim, M.G. 2013. The effects of adding melamine at different resin synthesis points of low mole ratio urea-melamine-formaldehyde (UMF) resins. BioResources 8: 5733-5748.

Maulana, S., Busyra, I., Fatrawana, A., Hidayat, W., Sari, R.K., Sumardi, I., Wistara, I.N.J., Lee, S.H., Kim, N.H., Febrianto, F. 2017. Effects of steam treatment on physical and mechanical properties of bamboo oriented strand board. Journal of the Korean Wood Science and Technology 45(6): 872-882.

Nuryawan, A., Park, B.D., Singh, A.P. 2014. Penetration of urea-formaldehyde resins with different formaldehyde/urea mole ratios into softwood tissues. Wood Science and Technology 48: 889-902. 
Park, B.D., Kang, E.C., Lee, S.M., Park, J.Y. 2016. Formaldehyde emission of wood-based composite panels with different surface lamination materials using desiccator method. Journal of the Korean Wood Science and Technology 44(4): 600-606.

Park, B.D., Lee, S.M., Roh, J.K. 2009. Effects of formaldehyde/urea mole ratio and melamine content on the hydrolytic stability of cured ureamelamine-formaldehyde resin. European Journal of Wood and Wood Products 67: 121-123.

Pizzi, A. 2003. Melamine-formaldehyde adhesives. In: Handbook of Adhesive Technology. Second edition. Marcel Dekker, New York, 653-679.

Properzi, M., Pizzi, A., Uzielli, L. 2001. Honeymoon MUF adhesives for exterior grade glulam. Holz als Roh- und Werkst 59: 413-421.

Sernek, M., Resnik, J., Kamke, F.A. 1999. Penetration of liquid urea-formaldehyde adhesive into beech wood. Wood and Fiber Science 31: 41-48.
Siimer, K., Kaljuvee, T., Pehk, T., Lasn, I. 2010. Thermal behaviour of melamine-modified ureaformaldehyde resins. Journal of Thermal Analysis and Calorimetry 99: 755-762.

Singh, A., Dawson, B., Rickard, C., Bond, J., Singh, A. 2008. Light, Confocal and Scanning Electron Microscopy of Wood-Adhesive Interface. Microscopy and Analysis 22: 5-8.

Su, W.Y., Subyakto, B., Nishimiya, T.H.K., Imamura, Y., Ishihara, S. 1998. Improvement of fire retardancy of plywood by incorporating boron or phosphate compounds in the glue. Journal of Wood Science 44: 131-136.

Tohmura, S.I., Inoue, A., Sahari, S.H. 2001. Influence of the melamine content in melamine-ureaformaldehyde resins on formaldehyde emission and cured resin structure. Journal of Wood Science 47: 451-457. 